\title{
Optimization of saving production cost in plastic jute sacks with dynamic programming
}

\author{
Rahmi M Sari ${ }^{1} *$, Mangara M Tambunan ${ }^{1}$, Khalida Syahputri $^{1}$, Anizar Anizar ${ }^{1}$, Ikhsan Siregar $^{1}$, and Indah Rizkya $\mathrm{T}^{1}$ \\ ${ }^{1}$ Universitas Sumatera Utara, Department of Industrial Engineering, Faculty of Engineering, Medan, Indonesia
}

\begin{abstract}
The plastic jute sack is one of the most popular rice packaging products in the market. One type of plastic jute sack used is LDPE type. The LDPE sacks used for rice packaging often-experiencing fluctuations in market demand. Fluctuating demand is a certain problem for companies in determining the number of production to meet the demand. It can be seen from the frequent over production companies and stock out at each period. Overproduction problem has an impact to increase production costs. Stock resulted in lost sales experienced adversely affected the company, especially from production cost. Based on the problems, the company must immediately performs an optimal production planning to handle various problems in the company. One method for saving the optimal cost production can be used is dynamic programming. This method aims to obtain the optimal number of production accordance to market demand. This research is done to reduce cost by optimizing number of production. Method that used to solve the problem is dynamic programming. By using this method, the company will obtain optimum production number with minimum production cost and considering total capacity available of the company. From the dynamic programming results obtained optimal production number with cost savings about $2.1 \%$.
\end{abstract}

\section{Introduction}

Industrial world growing fastly causing competition among companies. Every company required to make continuous improvement and optimize production process. Optimal production process done by good production planning. A production plan said to be good if the plan was met the demand from consumers by using minimum cost to get optimal result. Production planning is very important to determine the continuity of production operational [1]. Production planning is an activity related to determining what should produce, the quantity produced, when it is produced and the number of resources needed to get the number of production. Production planning is carried out to plan the flow of incoming and outgoing materials from an industry by optimizing profits.

Production management as the process of decisionmaking related to production processes so that the resulting goods or services are produced according to specification in the amounts and by the schedule demanded and at minimum cost. In making decision on production planning, the production quantity for each period as well as that of each product is stated. Some key reasons for developing this kind of plan include, supply the finished products as specified in sales programmer after or before the due date; ensures a balance or economic utilization of labour, plant and capital in the most efficient possible way [2][3].

The plastic jute sack is one of the most popular packaging products in the market. The development of industry with high business competition causes plastic jute sack used wider than ordinary jute sack. In making of plastic jute bags, company is often experiencing difficulty in making decisions for the determination of optimal production plans. So far, the company makes production planning only by making predictions based on demand in the simply previous period. Fluctuating market demand causes a mismatch in production volumes with demand volume. This discrepancy causes the company experiencing excess production or stock shortages. Excess production has an impact on increasing of storage costs while stock shortages has an impact to the addition of working hours or overtime to meet the demand. Therefore, an approach is needed to produce optimal production planning.

The method used in this study is dynamic programming. Dynamic programming is a branch of operations research. It is a process of multi-stage decision which is mainly used to solve problems of multi-objective decision to achieve the optimal results [4-7]. A general dynamic programming model can be easily formulated for a single dimension process from the principle of optimality. The programming situation includes a certain quantity of economic resources (space, finance, people, and equipment) which is allocated to a number of different activities[8].

Some research had been done related to production planning [9] Production planning studies in convection company using goal programming. This research is used to determine combination of number of products by considering multiple objectives, namely maximizing

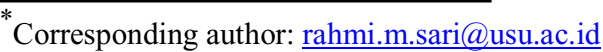


revenue, minimizing production costs and maximizing machine usage [10]. Production planning using hybrid fuzzy multi-objective nonlinear programming model with different goal priorities also done in a fuzzy environment to minimize total production costs, carrying and back ordering costs and costs of changes in workforce level (quantitative objectives) and maximize total customer satisfaction (qualitative objective) including the inventory level, demand, labor level, machines capacity, and warehouse space [3]. Production planning using dynamic programming studied in animal feed mills to minimizing the total costs of production and the annual inventory, while at the same time meeting the customer's demand.

In the previous research, researchers tried to planning production in many different areas by using different techniques. In this research, production planning is done by using dynamic programming method. This method is very little used in doing production planning due to the use of more complex method than the other methods. This purpose of this research is saving production cost by planning the optimal number of production.

\section{Methodology}

The research was conducted in one of the plastic jute sack making industry in Medan area. This industry produces plastic jute sack with size of $50 \mathrm{~kg}$ and become an object in this research. Research is done by using dynamic programming method to handle the problem of production planning company. Steps in the process of this research begins by forecasting demand. Forecasting is done to estimate the number of production volume of plastic jute sack for the next period. The forecast calculation uses the time series method considering the standard deviation value estimation as the best forecasting method selection. The next step is to calculate the production cost of regular time, over time and save costs which is three costs will input in determining the equation of recursive function. The next step is to plan production volume with dynamic programming method. Dynamic programming begins with identifying input variables and identifying decision variables. The next step is to formulate the recursive function equation with the recursive backward. The recursive function equation used is

$$
\begin{gathered}
F_{n}\left(I_{n}\right)=\operatorname{Min}\left[K_{n}\left(X_{n}\right)+H\left(I_{n}+X_{n}-D_{n}\right)\right]+F_{n}\left(X_{n}, I_{n}\right)+ \\
F^{*}{ }_{n-1}\left(\left(I_{n}+X_{n}-D_{n}\right)\right.
\end{gathered}
$$

With $\mathrm{Xn}$ is the scheduled production periodt $\mathrm{n}$, Dn is the estimation of demand period $\mathrm{n}$, In is the end-period inventoryt $_{\mathrm{n}}, \mathrm{Kn}(\mathrm{Xn})$ is production cost $\mathrm{Xn}, \mathrm{H}$ is saving cost, and $F^{*} n-1$ is minimum cost for previous 1 year period. By using this recursive function equation, model determined by dynamic programming method to get the result of production cost at each period (stage).

\section{Result and discussion}

[3][4][5] In order to solve the problems using dynamic programming, there are several steps that should be done to get the result.

\subsection{Demand forecasting}

Determination the number of market demand for the next period is done forecasting method. Forecasting is done by time series method. Demand forecasting results for the next period can be seen in Figure 1.

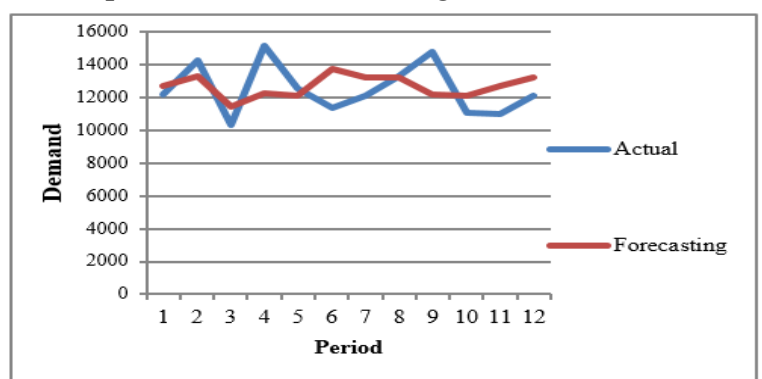

Fig. 1. Comparison between forecasting and actual demand.

According to Fig. 1, it can be seen that the number of market demand forecasting result is around the actual demand of the company and shows the result of representative forecasting to actual demand of company. Market demand for plastic jute bags fluctuates at each period. The highest demand occurs in period 6 about 13736 units and the lowest demand occurs in period 3 about 11442 units.

\subsection{Dynamic programming}

This method is done by identifying input variables and decision variables. The input variables are forecasting result, production capability, inventory quantity, production cost variable, and save cost which is decision variable is a determination of quantity of product to produced and number of inventory at each period. Based on the input variables, the recursive function equation obtained with time of regular cost is Rp.1999 / unit, overtime cost of Rp.636 / unit, and save cost Rp.13 / unit. Recursive function equation at each sub-step of production plan problem is backward recursive as follows.

$$
\begin{aligned}
& \mathrm{F}_{12} *\left(\mathrm{I}_{12}\right)=1999 \mathrm{X}_{12}+\left(\mathrm{X}_{12}-11437\right) 636+ \\
& 13\left(\mathrm{I}_{12}+\mathrm{X}_{12}-\mathrm{D}_{12}\right) \\
& \mathrm{F}_{11} *\left(\mathrm{I}_{11}\right)=1999 \mathrm{X}_{11}+\left(\mathrm{X}_{11}-12476\right) 636+ \\
& 13\left(\mathrm{I}_{11}+\mathrm{X}_{11}-\mathrm{D}_{11}\right)+\mathrm{F}_{12} *\left(\mathrm{I}_{12}\right) \\
& \mathrm{F}_{10} *\left(\mathrm{I}_{10}\right)=1999 \mathrm{X}_{10}+\left(\mathrm{X}_{10}-11957\right) 636+ \\
& 13\left(\mathrm{I}_{10}+\mathrm{X}_{10}-\mathrm{D}_{10}\right)+\mathrm{F}_{11} *\left(\mathrm{I}_{11}\right) \\
& \mathrm{F}_{9} *\left(\mathrm{I}_{9}\right)=1999 \mathrm{X}_{9}+\left(\mathrm{X}_{9}-11957\right) 636+13\left(\mathrm{I}_{9}+\mathrm{X}_{9}-\mathrm{D}_{9}\right) \\
& \quad+\mathrm{F}_{10} *\left(\mathrm{I}_{10}\right)
\end{aligned}
$$




$$
\begin{aligned}
\mathrm{F}_{8} *\left(\mathrm{I}_{8}\right)= & 1999 \mathrm{X}_{8}+\left(\mathrm{X}_{8}-12996\right) 636+13\left(\mathrm{I}_{8}+\mathrm{X}_{8}-\mathrm{D}_{8}\right) \\
& +\mathrm{F}_{9} *\left(\mathrm{I}_{9}\right) \\
\mathrm{F}_{7} *\left(\mathrm{I}_{7}\right)= & 1999 \mathrm{X}_{7}+\left(\mathrm{X}_{7}-12996\right) 636+13\left(\mathrm{I}_{7}+\mathrm{X}_{7}-\mathrm{D}_{7}\right) \\
& +\mathrm{F}_{8} *\left(\mathrm{I}_{8}\right) \\
\mathrm{F}_{6} *\left(\mathrm{I}_{6}\right)=1999 \mathrm{X}_{6}+\left(\mathrm{X}_{6}-13516\right) 636+13\left(\mathrm{I}_{6}+\mathrm{X}_{6}-\mathrm{D}_{6}\right) & \\
& +\mathrm{F}_{7} *\left(\mathrm{I}_{7}\right) \\
\mathrm{F}_{5} *\left(\mathrm{I}_{5}\right)= & 1999 \mathrm{X}_{5}+\left(\mathrm{X}_{5}-13516\right) 636+13\left(\mathrm{I}_{5}+\mathrm{X}_{5}-\mathrm{D}_{5}\right) \\
& +\mathrm{F}_{6} *\left(\mathrm{I}_{6}\right) \\
\mathrm{F}_{4} *\left(\mathrm{I}_{4}\right)= & 1999 \mathrm{X}_{4}+\left(\mathrm{X}_{4}-13516\right) 636+13\left(\mathrm{I}_{4}+\mathrm{X}_{4}-\mathrm{D}_{4}\right) \\
& +\mathrm{F}_{5} *\left(\mathrm{I}_{5}\right)
\end{aligned}
$$

$$
\begin{aligned}
\mathrm{F}_{3} *\left(\mathrm{I}_{3}\right)= & 1999 \mathrm{X}_{3}+\left(\mathrm{X}_{3}-13516\right) 636+13\left(\mathrm{I}_{3}+\mathrm{X}_{3}-\mathrm{D}_{3}\right) \\
& +\mathrm{F}_{4} *\left(\mathrm{I}_{4}\right) \\
\mathrm{F}_{2} *\left(\mathrm{I}_{2}\right)= & 1999 \mathrm{X}_{2}+\left(\mathrm{X}_{2}-13516\right) 636+13\left(\mathrm{I}_{2}+\mathrm{X}_{2}-\mathrm{D}_{2}\right) \\
& +\mathrm{F}_{3} *\left(\mathrm{I}_{3}\right) \\
\mathrm{F}_{1} *\left(\mathrm{I}_{1}\right)= & 1999 \mathrm{X}_{1}+\left(\mathrm{X}_{1}-13516\right) 636+13\left(\mathrm{I}_{1}+\mathrm{X}_{1}-\mathrm{D}_{1}\right) \\
& +\mathrm{F}_{2} *\left(\mathrm{I}_{2}\right)
\end{aligned}
$$

The calculation of production and inventory quantities by this method is done by using collected data. Recapitulation of production calculation and inventory plan can be seen in Table 1 .

Table 1. Recapitulation of production and inventory plans.

\begin{tabular}{|c|c|c|c|c|c|}
\hline Period & $\begin{array}{c}\text { Demand } \\
\text { (unit) }\end{array}$ & $\begin{array}{c}\text { Volume of Production } \\
\text { (unit) }\end{array}$ & $\begin{array}{c}\text { Initial Inventory } \\
\text { (unit) }\end{array}$ & $\begin{array}{c}\text { Net Inventory } \\
\text { (unit) }\end{array}$ & $\begin{array}{c}\text { Cost Accumulation } \\
\text { (Rp) }\end{array}$ \\
\hline January & 12746 & 12476 & 210 & 270 & 247.939 .548 \\
\hline February & 13276 & 12996 & 270 & 280 & 225.101 .983 \\
\hline March & 11442 & 12996 & 280 & 235 & 202.264 .418 \\
\hline April & 12239 & 11957 & 235 & 282 & 179.426 .854 \\
\hline May & 12124 & 11957 & 282 & 167 & 156.589 .289 \\
\hline June & 13736 & 13516 & 167 & 220 & 133.751 .724 \\
\hline July & 13232 & 12996 & 220 & 236 & 110.914 .159 \\
\hline August & 13233 & 12996 & 236 & 237 & 88.076 .594 \\
\hline September & 12217 & 11957 & 237 & 260 & 65.239 .030 \\
\hline October & 12146 & 11957 & 260 & 189 & 42.401 .465 \\
\hline November & 12726 & 12476 & 189 & 250 & 19.563 .900 \\
\hline December & 13231 & 11437 & $\mathbf{1 4 9 7 1 7}$ & 0 & 2626 \\
\hline Total & $\mathbf{1 5 2 3 4 8}$ & 140.837 .565 \\
\hline
\end{tabular}

The calculation of production cost cumulative for the next 12 periods using dynamic programming method obtained a minimum cost Rp. 247,939,548-, with net inventory of 2626 units. Production planning by this method eliminates lost sales because the production is done based on market demand needed.

\subsection{Comparison between production cost by dynamic programming method and company actual system}

Calculation of production cost for the next period shows that total cost of production planning and inventory with company actual system value of $\mathrm{Rp}$. 253.257.965-, greater than the total cost of production planning and inventory with dynamic programming method. The calculation of saving cost can be seen as follows.

Percentage $=\frac{\text { Rp.253.257.965-Rp.247.939.548 }}{\text { Rp.253.257.965 }}$

$$
=2,1 \%
$$

Dynamic programming method save production cost of Rp. 5.318.417-, or 2.1\% when compared to applied system by the company during that period. By this method, the company eliminates e lost sales and has a lower inventory level than company system. 


\section{Conclusions}

By dynamic programming method, the company will obtain optimum production number with minimum production cost and considering the total capacity available of the company.

Authors would like to thank to Universitas Sumatera Utara forfunding the financial support for publishingthis paper.

\section{References}

1. S. Sinulingga, MetodePenelitian, (USU Press, Medan, 2013)

2. M. Teslang, Industrial Engineering and Production Management, (Ramnagar, New Delhi, 2000)

3. O. Olanrele, K. A. Olaiya, T. A. Adio, Application of Dynamic Programming Model to ProductionPlanning, in an Animal Feedmills, IISTE 3, 5 (2013)

4. L. Li Jun, W. Dasheng, Optimization Model for Production Planning Based on Dynamic Programming, International Conference on Artificial Intelligence and Computational Intelligence, (2009)

5. J. Liping, Z. Bo, Application of Dynamic Programming on Allocation of Water Resources, Yellow River 30, 5 (2008)

6. H. Yunquan, G. Yaohuang, OperationalResearch Tutorial, (Tsinghua University Press,Beijing, 1998)

7. X. Junxing,Z. Jinping, Research On Control Model of Sparepart's inventory Based OnDP.Microcomputer Information 33, 9 (2008)

8. L.P. Michael, Planning and Scheduling in Manufacturing and Services, (Springer, New York, 2005)

9. W. Anggraeni, R. Aulia V, R. Tyasnurita, J. Permatasari, Planning Optimization Using Goal Programming Method in HabibahBusana, Journal of Advanced Management Science 3, 4 (2015)

10. A. Jamalnia, M. Ali S, A hybrid fuzzy goal programmingapproach with different goal priorities to aggregate production. ComputIndEng56, (2009) 